\title{
Selective monitoring of peptidase activities with synthetic polypeptide substrates and polyion-sensitive membrane electrode detection
}

\author{
IN SUK HAN, ${ }^{*}$ NARAYANAN RAMAMURTHY, ${ }^{\dagger}$ JONG H. YUN, ${ }^{*}$ ULRICH SCHALLER, ${ }^{\dagger}$ MARK E. \\ MEYERHOFF, ${ }^{\dagger}$ AND VICTOR C. YANG*,1 \\ *College of Pharmacy and ${ }^{\dagger}$ Department of Chemistry, University of Michigan, Ann Arbor, Michigan 48109- \\ 1065, USA
}

\begin{abstract}
A novel method to monitor specific peptidase activities in biological samples as complex as undiluted plasma/blood is described. The approach is based on the design of synthetic polypeptide substrates in which di- or triarginine sequences are linked to each other via one or more other amino acids recognized specifically by the peptidase to be determined. Detection of chymotrypsin and renin activities using synthetic substrates P4 (F-R-R-R-F-V-R-R-F-NH ${ }_{2}$ ) and P5 (R-R-R-L-LR-R-L-L-R-R-R), respectively, serves to demonstrate the principles of this new assay system. A polyion-sensitive membrane electrode, prepared by doping polymer films with dinonylnaphthalenesulfonate (DNNS), is shown to exhibit significant nonequilibrium electromotive force (EMF) responses toward these and other polycationic substrates at microgram/milliliter levels under physiological conditions. The same electrode, however, exhibits much smaller total EMF response toward the shorter fragments of the synthetic peptides generated by peptidase activity; hence, the addition of peptidase to a solution containing the synthetic substrate yields a change in electrode EMF response, the rate of which is proportional to the activity of peptidase present. Other synthetic polycationic peptides as well as natural polycationic peptides (e.g., protamine) that lack specific cleavage sites for chymotrypsin and renin, yet are detected by the DNNSbased membrane electrode, do not elicit any significant change in EMF response in the presence of the peptidases, confirming the feasibility and utility of the proposed bioanalytical method. - Han, I. S., Ramamurthy, N., Yun, J. H., Schaller, U., Meyerhoff, M. E., Yang, V. C. Selective monitoring of peptidase activities with synthetic polypeptide substrates and polyion-sensitive membrane electrode detection. FASEB J. 10, 1621 - 1626 (1996)
\end{abstract}

Key Words: polycationic sensor - electrochemical potential $\cdot$ chymotrypsin $\cdot$ renin

PEPTIDASES ARE ESSENTIAL for biological activities in all living organisms, including viruses, and hence the accu- rate measurement of peptidase activities is critical in research relating to studying and/or potentially modulating (via pharmaceuticals) cell proliferation, cell differentiation, nutrient digestion, morphogenesis, and blood clotting $(1,2)$. Although nearly 400 peptidases have been identified and characterized (1), relatively few simple bioanalytical methods are available to monitor, in real time, specific peptidase activities in complex biological samples. Even though a wide range of chromogenic substrates have been prepared for selective detection of certain peptidases (2), such fluorescence or absorption methods are not amenable to direct monitoring of peptidase activities in highly colored or turbid milieus, such as cell suspensions or undiluted blood samples. Further, suitable chromogenic substrates are not available for certain peptidases that recognize and cleave at sites containing a sequence of at least two amino acids [e.g., renin (1-3), which recognizes and cleaves X-L-L-Y sequences]. In such instances, only more costly and cumbersome radioimmunoassays or radioautography of separated peptide fragments can be used to assess catalytic activity $(3,4)$.

Herein, we introduce a completely new and simple electrochemical methodology for detecting specific peptidase activities via use of synthetic polypeptide substrates in combination with polyion-sensitive membrane electrode detection. This new approach is based on the observation that appropriately formulated polymer membrane type ionselective electrodes exhibit a significant electromotive force $(\mathrm{EMF})^{2}$ response to low levels of biologically important polyions, including heparin $(5,6)$ and protamine $(7)$, in samples as complex as whole blood $(8,9)$, but do not respond to much smaller di- and trisaccharide/peptide fragments of these polyion structures. Potentiometric response toward the larger polyion species has been ascribed to favorable extraction of the polyions into the membrane

\footnotetext{
' Correspondence: College of Pharmacy, 428 Church St., University of Michigan, Ann Arbor, MI, 48109-1065, USA.

${ }^{2}$ Abbreviations: BTEE, N-benzoyl-L-tyrosine ethyl ester; DNNS, dinonylnaphthalenesulfonate; DOS, bis(2-ethylhexyl) sebacate; EMF, electromotive force; PVC, high molecular weight poly(vinyl chloride); THF, tetrahydrofuran.
} 
phase via cooperative ion pairing with lipophilic ion exchange sites doped within the plasticized poly(vinyl choride) films $(10,11)$. This extraction process yields a nonequilibrium steady-state change in the phase boundary potential at the membrane/sample interface. The thermodynamics of polyion extraction, and hence, the magnitude of EMF response toward given polyion structures, has been shown to be highly dependent on the charge density and chain length of the polyion (11). The chain length-dependent response behavior is potentially useful for monitoring peptidase activities. Indeed, in preliminary experiment membrane electrodes formulated to respond to argininerich protamine were used to monitor trypsin activity by directly following the digestion of protamine potentiometrically via the change in EMF response as protamine was degraded to smaller peptide fragments (7).

To render this approach more broadly applicable and selective for detecting other peptidases, we report here that simple polymer membrane electrodes prepared using a charged ionophore such as DNNS $(12,13)$ as the membrane active component also exhibit significant EMF response to synthetic, arginine-rich polycationic peptides. By designing the peptide to contain one or several amino acids between the arginine-rich segments, highly selective real-time detection of specific peptidases that cleave at the added amino acid residue (or residues) sites along the peptide chain can be achieved. As models, we use synthetic peptides P4 (F-R-R-R-F-V-R-R-F- $\mathrm{NH}_{2}$, chemically amidated on carboxyl terminus) and P5 (R-R-R-L-L-R-R-LL-R-R-R) for monitoring chymotrypsin and renin activities, respectively.

\section{MATERIALS AND METHODS}

\section{Chemicals}

High molecular weight poly(vinyl chloride) (PVC), bis(2-ethylhexyl) sebacate (DOS), and tetrahydrofuran (THF) were from Fluka Chemika Biochemika (Ronkonkoma, N.Y.). Protamine sulfate (from herring, grade III), $\alpha$-chymotrypsin (sodium-p-tosyl-L-lysine chloromethyl ketone or TLCK treated), and renin were from Sigma Chemical Co. ( $\mathrm{St}$ Louis, Mo.). Calcium DNNS was kindly provided by King Industries (Norwalk, Conn.). Fresh frozen human plasma was from the American Red Cross (Detroit, Mich.). Synthetic peptides P1, P2, P3, P4, and P5 (see Table 1 for sequences) were synthesized and amidated at the Protein and Carbohydrate Research Center at the University of Michigan.

\section{Preparation of polycation-sensitive tubular membrane} electrodes

Polycation-sensitive tubular membrane electrodes were prepared as described previously for polyanion (heparin)-sensitive electrodes (9), except that the charged ionophore DNNS at 1 wt \% was substituted for tridodecylmethylammonium chloride as the membrane cocktail additive. The membrane casting solution was prepared by dissolving 200 mg of the membrane components (DNNS: PVC: DOS = 1:49.5:49.5 w/ w/w) in $2.5 \mathrm{ml}$ THF. This casting solution was dip coated (12 times at 30 min intervals) over copper wires protruding from a narrow bore tygon tube and then dried overnight (see ref 9). The copper wire was then carefully removed and the tube was filled with $15 \mathrm{mM} \mathrm{NaCl}$ solution.
$\mathrm{An} \mathrm{Ag} / \mathrm{AgCl}$ reference electrode was inserted into the inner bore of the tube to complete fabrication of the electrode. Before use, all tubular electrodes were presoaked in a $15 \mathrm{mM} \mathrm{NaCl}$ solution for at least $6 \mathrm{~h}$.

\section{Measurement of EMF response to synthetic and natural peptides}

The EMF response of the tubular DNNS-based membrane electrodes toward different synthetic and natural polycationic peptides was measured vs. a miniature external $\mathrm{Ag} / \mathrm{AgCl}$ reference electrode (Bioanalytical Systems Inc., West Lafayette, Ind.). The EMF data were recorded via a Macintosh IIcx computer coupled with a NB-MIO-16x analog/ digital input/output board (National Instruments, Austin, Tex.) and a custom-built electrode interface/amplifier module controlled by LabView 2 software (National Instruments) as described previously (14). The potentiometric response of the electrodes was determined by adding aliquots of P1-P5 and protamine stock solutions $(1 \mathrm{mg} / \mathrm{ml})$ to $5 \mathrm{ml}$ of a well-stirred $50 \mathrm{mM}$ Tris- $\mathrm{HCl}$ buffer, $\mathrm{pH} 7.4$, containing 0.12 $\mathrm{M} \mathrm{NaCl}$. Unless otherwise specified, the response was recorded $5 \mathrm{~min}$ after addition of the aliquot.

\section{Measurement of chymotrypsin and renin activities using} tubular polycation-sensitive membrane electrode

Chymotrypsin (with activity of 0.025-3 N-benzoyl-L-tyrosine ethyl ester [BTEE] U/1) was detected using P4 as the selective substrate. Measurements were carried out in $5 \mathrm{ml}$ of $50 \mathrm{mM}$ Tris- $\mathrm{HCl}(\mathrm{pH} \mathrm{7.4,0.12}$ $\mathrm{M} \mathrm{NaCl}$ ) and undiluted plasma at room temperature. Experiments were performed by adding an aliquot of peptide $\mathrm{P} 4$ to buffer or plasma to yield a final concentration of $5 \mu \mathrm{g} / \mathrm{ml}$. Once the EMF response was relatively stable (after $5 \mathrm{~min}$ ), different amounts of chymotrypsin were added and the decrease in potentiometric response toward the P4 substrate corresponding to enzymatic digestion was monitored with time. The rates of initial EMF change $\left(-l_{E} / \mathrm{t}\right)$ were determined from the initial slope of potential vs. time recordings.

The potentiometric enzyme assay for renin activity using the synthetic $\mathrm{P} 5$ peptide as the selective substrate was performed using $\mathbf{5} \mathbf{~ m l}$ volumes of $50 \mathrm{mM}$ Tris- $\mathrm{HCl}(\mathrm{pH} 7.4,0.12 \mathrm{M} \mathrm{NaCl})$ in a series of test tubes. The solutions of the peptides $\mathrm{P} 5(5 \mu \mathrm{g} / \mathrm{ml}$ in the Tris- $\mathrm{HCl}$ buffer $)$ as well as P4 $(5 \mu \mathrm{g} / \mathrm{ml}$; as control) with different amounts of added renin $(0.001-0.02 \mathrm{U} / \mathrm{ml})$ were incubated for $4 \mathrm{~h}$ at $37^{\circ} \mathrm{C}$. For each peptide, a set of three electrodes was then placed into the solution with the highest renin activity, and the potential was recorded after 3 and $4 \mathrm{~min}$ for peptide $\mathrm{P} 5$ and $\mathrm{P} 4$, respectively. The electrodes were then regenerated for $3 \mathrm{~min}$ in $2 \mathrm{M} \mathrm{NaCl}$ and for $2 \mathrm{~min}$ in $0.12 \mathrm{M} \mathrm{NaCl}$ before they were used to measure the solution with the next highest renin activity. This procedure was repeated until the last sample with the lowest renin activity was measured.

\section{RESULTS AND DISCUSSION}

Figure 1 shows the calibration curves obtained with the tubular DNNS-based polycation-sensitive membrane electrode toward five different synthetic peptides and native protamine at various concentrations. As shown, in all the cases studied, the EMF response saturates at about $15 \mu \mathrm{g} /$ $\mathrm{ml}$. Table 1 summarizes the EMF response of these peptides and protamine at two different concentrations; the lower concentration $(5 \mu \mathrm{g} / \mathrm{ml})$ was used for all subsequent peptidase assays, whereas the higher concentration $(25 \mu \mathrm{g} /$ $\mathrm{ml}$ ) reflects the equilibrium EMF response that is the maximum possible potential change toward the respective peptide or protein. The DNNS-based membrane electrode exhibits significant response to protamine and the smaller 


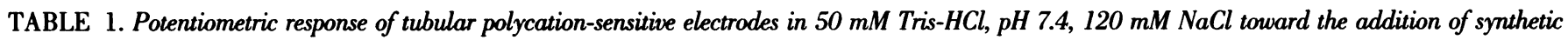
peptides (Pl-P5) or native protamine to a final concentration of 5 or $25 \mu \mathrm{g} / \mathrm{ml}$. Peptides P2-P4 were amidated at the carboxyl terminus.

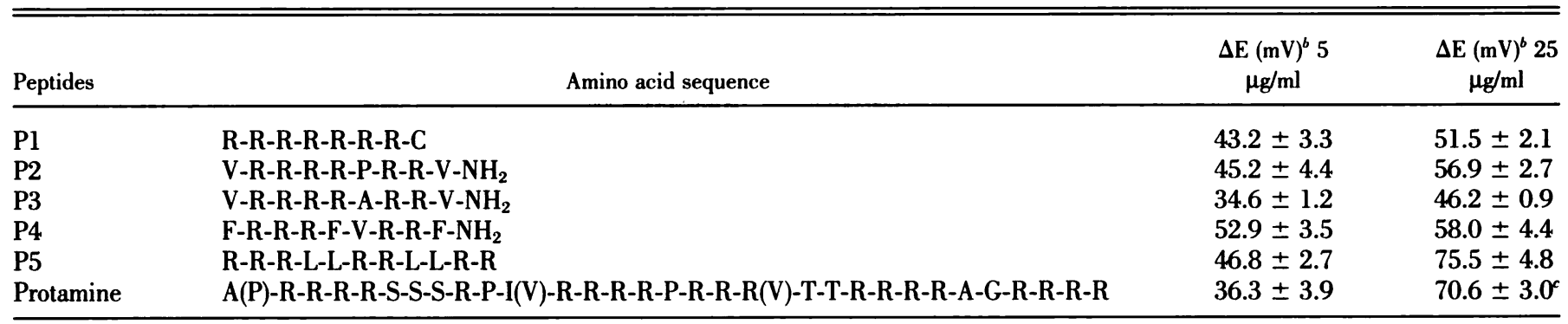

average from three electrodes; standard deviation given.

${ }^{b}$ Response toward $50 \mu \mathrm{g} / \mathrm{ml}$ protamine.

polycationic peptides even in the presence of physiological levels of sodium ions. At low substrate concentrations, the EMF response to protamine, which contains $20 \mathrm{~L}$-arginine residues among its total of 31 amino acids, is actually less than the Pl peptide, which contains seven arginines of its eight total amino acids. It is likely that the short sequences of hydrophilic amino acids within the protamine structure, such as di-and tri-serine/threonine, decrease the overall extraction of protamine into the organic membrane phase of the electrode. Addition of hydrophobic amino acids in the form of proline, phenylalanine, and leucine to the primarily polyarginine peptide structures further enhances the overall thermodynamics of peptide extraction, as evidenced by the greater EMF responses observed for peptides P2, P4, and P5, respectively. (NOTE: the carboxyl terminus of peptides $\mathrm{P} 2-\mathrm{P} 4$ was also amidated to enhance extraction into cation exchange membrane of the electrode.)

Based on the above observations, the oligopeptides P4 and P5 were investigated as potential substrates for selective monitoring of chymotrypsin and renin activities. Chy-

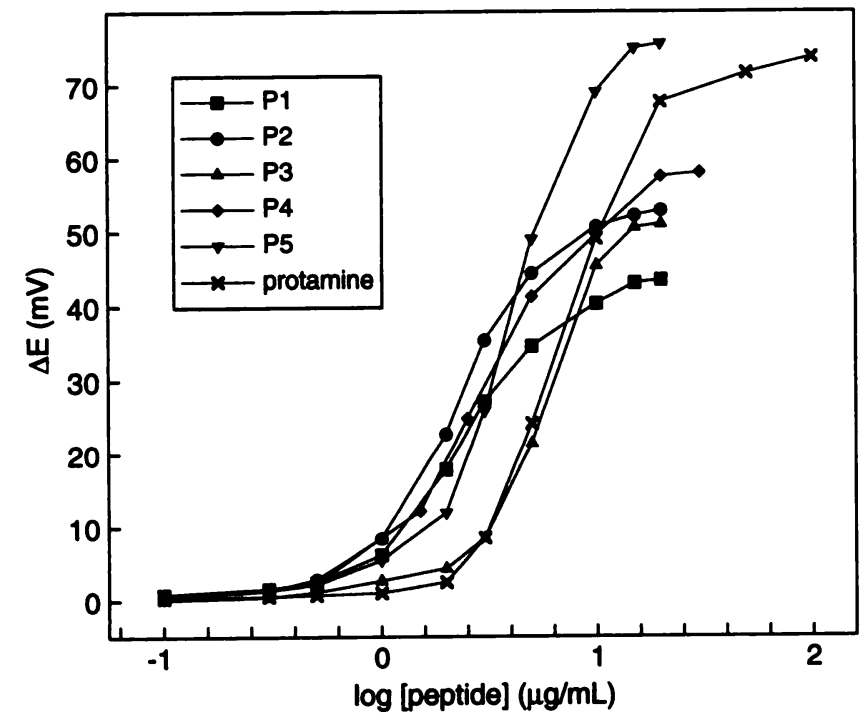

Figure 1. Potentiometric response of tubular polycation-sensitive membrane electrodes (average of three) in $50 \mathrm{mM}$ Tris- $\mathrm{HCl}, \mathrm{pH} \mathrm{7.4}$, $120 \mathrm{mM} \mathrm{NaCl}$ toward the addition of synthetic peptides P1-P5 and protamine. motrypsin hydrolyzes polypeptides primarily at the carbonyl group of aromatic amino acids along the chain (phenylalanine, tyrosine, and tryptophan), although it also exerts activity at leucine residues. Thus, peptide $\mathrm{P} 4$ with a hydrophobic Phe-Val link between Arg-Arg-Arg and Arg-Arg sequences should be a good substrate for chymotrypsin activity. As shown in Fig. 2, when low concentrations of any of the peptides P1-P5 or native protamine are added to a stirred solution of Tris- $\mathrm{HCl}$ buffer, pH 7.4, containing $0.12 \mathrm{M} \mathrm{NaCl}$, the DNNS-based polymer membrane electrode immediately responds to the presence of these substrates, yielding a steady-state EMF response within about $5 \mathrm{~min}$. Upon addition of $0.05 \mathrm{U} / \mathrm{ml}$ of chymotrypsin, the response to peptide $\mathrm{P} 4$ and P5 are altered, with an immediate change in the negative potential direction. The slightly lower chymotrypsin activity toward peptide P5 is primarily due to the presence of a less favorable leucine cleavage site on the peptide. However, the response to protamine and the peptides P1-P3 was not

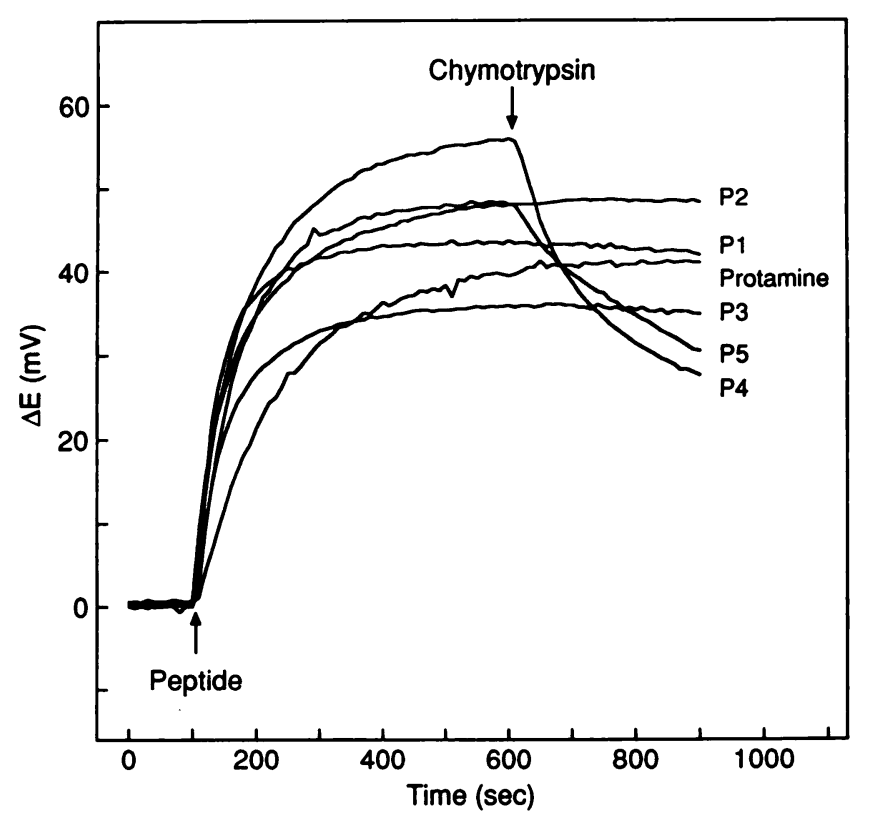

Figure 2. Potentiometric response of tubular polycation-sensitive membrane electrodes (average of three) in $50 \mathrm{mM}$ Tris- $\mathrm{HCl}, \mathrm{pH} \mathrm{7.4}$, $120 \mathrm{mM} \mathrm{NaCl}$ toward $5 \mu \mathrm{g} / \mathrm{ml}$ synthetic peptides (P1-P5) or native protamine before and after addition of $0.05 \mathrm{U} / \mathrm{ml}$ chymotrypsin. 
altered upon addition of chymotrypsin. Figure 3 further illustrates the potential change for peptide P4 in the presence of different chymotrypsin activities and, in the insert, the initial rate of EMF change upon addition of the peptidase is shown to be directly proportional to the amount of chymotrypsin activity added (in the range of 0.025 and $0.5 \mathrm{U} / \mathrm{ml}$ ). As estimated from the calibration curve in Fig. 1 , one $\mathrm{mV}$ of potential change is equivalent to the conversion of $0.3 \mathrm{nmol}$ of the P4 substrate. Thus, one (BTEE) unit of chymotrypsin would hydrolyze $3.88 \mathrm{nmol} \mathrm{P4}$ substrate per min, as determined from the slope of the curve in the insert of Fig. 3. It should be pointed out that the initial rate of EMF change levels off at higher enzyme concentrations. This is due to the limitation in the rate of reversibility of the electrode. Indeed, at the highest chymotrypsin concentration $(0.5 \mathrm{U} / \mathrm{ml})$, the rate of EMF change observed has already exceeded the maximum rate of reversibility (as obtained by measuring the rate of EMF reversal of the electrode from a solution containing the substrate to a solution without the substrate) of the electrode.

The principal advantage of using a polyion-sensitive membrane electrode to monitor peptidase activities lies in its potential use in rather complex samples. For example, Fig. 4 illustrates that even in undiluted human plasma, the tubular DNNS-based polyion-sensitive electrode exhibits a significant $\mathrm{EMF}$ response $(\mathrm{E}=27 \mathrm{mV})$ to peptide $P 4$, albeit less than in plain buffer solution $(\mathrm{E}=53 \mathrm{mV})$. Upon addition of chymotrypsin, again there is an immediate change in the EMF response in the negative potential

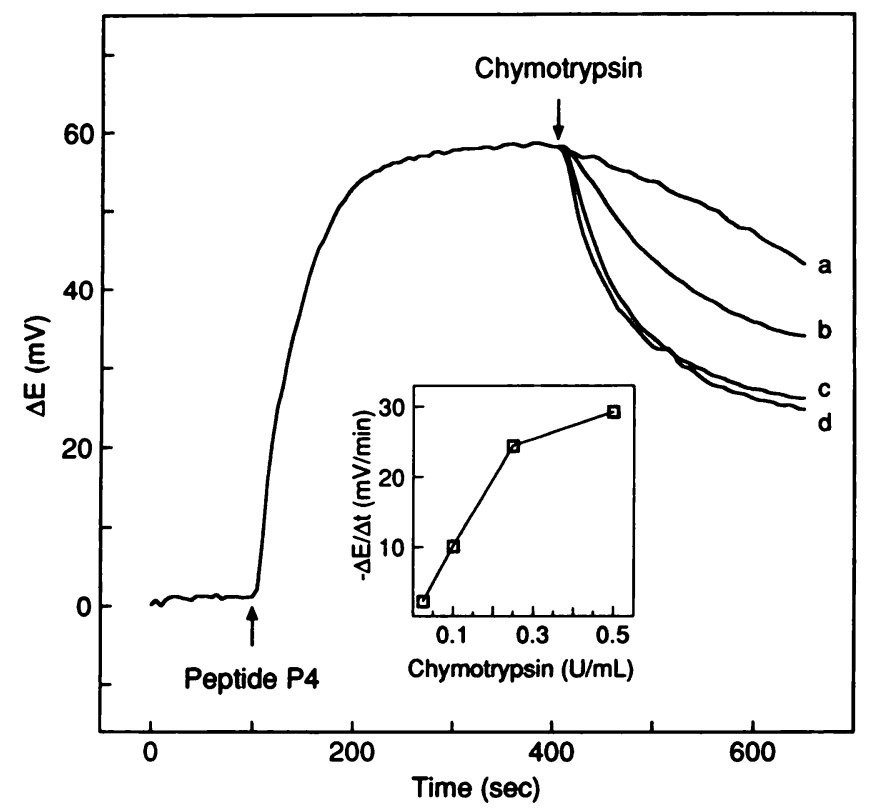

Figure 3. Potentiometric response of tubular polycation-sensitive membrane electrodes (average of two) in $50 \mathrm{mM}$ Tris- $\mathrm{HCl}, \mathrm{pH} \mathrm{7.4,} 120$ $\mathrm{mM} \mathrm{NaCl}$ toward $5 \mu \mathrm{g} / \mathrm{ml}$ synthetic peptide $\mathrm{P} 4$ and the effect of adding different amounts of chymotrypsin to this solution. a) 0.025 ; b) 0.1 ; $c$ ) $0.25 ; d) 0.5 \mathrm{U} / \mathrm{ml}$. The insert shows the rate of potential decrease $(-\mathrm{lE} /$ ti) immediately after addition of the protease as a function of the chymotrypsin activity.

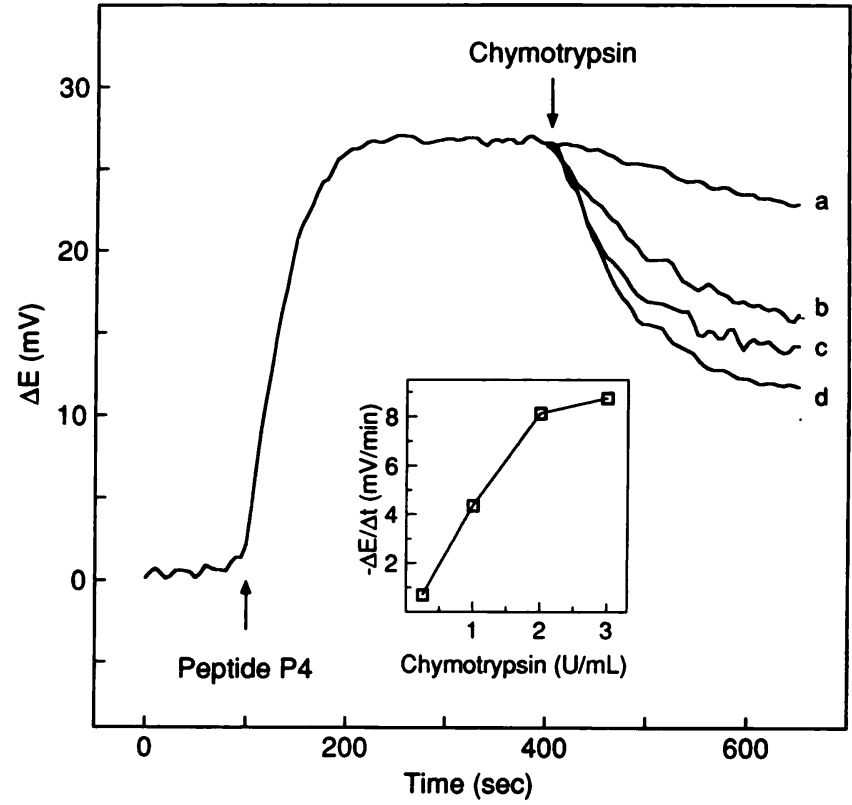

Figure 4. Potentiometric response of tubular polycation-sensitive membrane electrodes (average of two) in undiluted human plasma toward $5 \mu \mathrm{g} / \mathrm{ml}$ synthetic peptide P4 and the effect of adding different amounts of chymotrypsin to this solution: $a$ ) 0.25 ; b) 1.0 ; c) 2.0 ; d) 3.0 $\mathrm{U} / \mathrm{ml}$. The insert shows the rate of potential decrease $(-\mathrm{E} / \mathrm{h}) \mathrm{imme}-$ diately after addition of the protease as a function of the chymotrypsin activity.

direction, with the rate of change proportional to the amount of chymotrypsin added (in the range of 0.25-3 U/ $\mathrm{ml}$; see Fig. 4, insert) As anticipated, the overall sensitivity to chymotrypsin in undiluted plasma is somewhat less than that observed in buffer owing to the presence of endogenous plasma proteins that undoubtedly compete with peptide P4 as substrates for chymotrypsin activity. Nonetheless, the ability to monitor relative peptidase activities in real time within a sample as complex as undiluted plasma represents a significant advance in peptidase detection methodology, and could lead to the design of polycationic peptide substrates that can be used to measure more clinically relevant peptidase activities in plasma or whole blood (e.g., plasmin, factor Xa, etc.).

Since renin is known to hydrolyze Leu-Leu sequences within polypeptide chains (1-3), it is possible to detect renin activity electrochemically using the synthetic peptide P5. However, since the renin activity is much lower than that of chymotrypsin or other peptidases, it is necessary to use much longer incubation times to observe significant changes in the response of the DNNS-based membrane electrode toward P5 in the presence of renin (this is also true for the current radioimmunoassay used to detect renin activity) $(3,4)$. Using an incubation time of 4 $\mathrm{h}$ at $37^{\circ} \mathrm{C}$, a given concentration of peptide P5 $(5 \mu \mathrm{g} / \mathrm{ml})$ was incubated with different amounts of renin (in $5 \mathrm{ml}$ of buffer). At the end of this period, the EMF response of the DNNS-based tubular membrane electrode was measured for each solution and compared to the plain buffer (without renin or substrate). As shown in Fig. 5, renin digestion of 


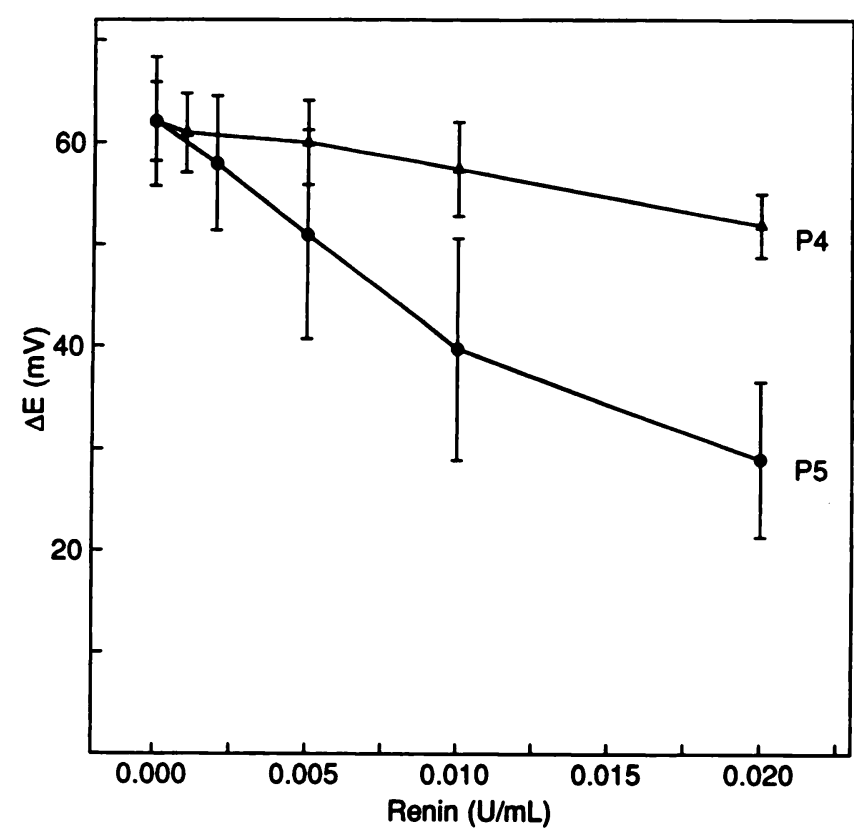

Figure 5. Renin activity measurement with tubular polycationm2Dsensitive membrane electrodes (average $\pm \mathrm{SD}$ of three electrodes given). Synthetic peptide $\mathrm{P} 4(\mathrm{O})$ and $\mathrm{P} 5(\nabla)(5 \mu \mathrm{g} / \mathrm{ml})$ were incubated in $5 \mathrm{ml} 50 \mathrm{mM}$ Tris- $\mathrm{HCl}, \mathrm{pH} 7.4,120 \mathrm{mM} \mathrm{NaCl}$ with different amounts of the protease renin $(0.001-0.02 \mathrm{U} / \mathrm{ml})$ for $4 \mathrm{~h}$ at $37^{\circ} \mathrm{C}$. After this incubation step, the electrodes were immersed into these solutions and the potential was recorded after $3(\mathrm{P} 5)$ or $4(\mathrm{P} 4) \mathrm{min}$.

P5 results in a decrease in the response to the substrate that is proportional to the amount of renin added. There was no change in EMF when the P5 peptide was incubated for $4 \mathrm{~h}$ in the absence of renin (data not shown). As also shown in Fig. 5, a much smaller change in the potentiometric responses was observed when the synthetic peptide P4 was incubated with the varying renin activities for the same length of time. The small but measurable digestion of peptide $\mathrm{P} 4$ is probably due to low levels of trypsin-like peptidase impurities within the renin preparation, as suggested by the manufacturer.

To confirm this, we conducted a colorimetric assay on the renin preparation to determine the trypsin-like peptidase contamination, using a chromogenic substrate, $\alpha$ benzoyl-L-arginine $p$-nitroanilide (BAPNA), for trypsin measurement. Our results show that in one unit of the renin preparation, there was about 0.3 BAPNA unit of trypsin-like peptidase activities. Because trypsin-like peptidases cleave primarily at the carbonyl group of Larginine residues, it should be possible to eliminate interference from trypsin-like peptidases simply by using $D$-arginine residues in the synthetic peptide to create the polycationic charge and L-amino acids as selective cleavage sites to link segments of $D$-arginine residues. Alternately, the addition of specific peptidase inhibitors to the assay mixture can be used to further decrease crossreactivity of the synthetic substrates with given peptidases, a common practice with existing peptidase assay methods (2).
The current study was established with the use of a conventional membrane electrode that requires a relatively large sample volume $(5 \mathrm{ml})$ and a long regeneration time $(5 \mathrm{~min}$ ) of the membrane for subsequent use. Because of the simple nature of the membrane technology involved, however, the membrane electrode could easily be fabricated into a disposable, miniature device to alleviate such problems. Indeed, mass production of disposable, coatedwire polyanion-sensitive membrane electrodes has been proved feasible, and their clinical utility in precisely and reproducibly measuring blood heparin concentrations in a sample volume as small as $0.2 \mathrm{ml}$ has been successfully demonstrated (9).

The concept of using synthetic polyion substrates to devise novel peptidase assays should not be limited to polycation peptide structures as demonstrated here. Indeed, use of polyanion-sensitive membrane electrodes $(5,6)$ in conjunction with judiciously designed peptides that are rich in glutamate and/or aspartate segments linked by appropriate amino acids that are recognized by given peptidases should also prove effective for monitoring specific peptidase activities. Whether working with polycation or polyanion peptides, the concept of incorporating suitable cleavage sites into synthetic polyion peptides and detecting the degradation of these substrates directly with newly developed polyion-sensitive membrane electrodes appears to be a promising new technology especially well suited to monitoring more clinically important peptidase such as thrombin, factor $\mathrm{Xa}$, tissue plasminogen activator, collagenase, etc., in undiluted blood samples and tissue culture samples. Alternatively, the new technology can also be modified to detect the activity of inhibitors specific for these peptidases. Efforts toward this direction are currently in progress in our laboratories.

This work was supported in part by grants from the National Institutes of Health (HL38353, HL55461, and GM-28882). U.S. gratefully acknowledges the Swiss National Science Foundation for financial support. The authors thank Ms. Tanya Wang and Ms. Lai-Ming Lee for assistance in the preparation of this manuscript.

\section{REFERENCES}

1. Enzyme nomenclature. (1992) Recommendations (1992) of the Nomenclature Committee of the International Union of Biochemistry and Molecular Biology, pp. 371-421, Academic Press, San Diego

2. Barrett, A. J., and McDonald, J. K. (1980) Mammalian Proteases: A Glossary and Bibliography, Vols. 1 and 2, Academic Press, New York

3. Slater, E. E. (1981) Renin. Methods Enzymol. 80, 427-442

4. Dupont (1991) Angiotensin I [ $\left.{ }^{125} \mathrm{I}\right]$ radio-immunoassay kit, NEA-104, 105 Instruction Manual

5. Ma, S. C., Meyerhoff, M. E., and Yang, V. C. (1992) Heparin-responsive electrochemical sensor: a preliminary study. Anal. Chem. 64, 694-697

6. Ma, S. C., Fu, B., Meyerhoff, M. E., and Yang, V. C. (1993) Electrochemical sensor for heparin: further characterization and bioanalytical applications. Anal. Chem. 65, 2078-2084

7. Yun, J. H., Meyerhoff, M. E., and Yang, V. C. (1995) Protamine-sensitive polymer membrane electrode: characterization and bioanalytical applications. Anal. Biochem. 224, 212-220

8. Yun, J. H., Lee, L. M., Wahr, J. A., Fu, B., Meyerhoff, M. E., Yang, V. C. (1995) Clinical application of disposable heparin sensors: blood heparin measurements during open heart surgery. ASAIO J. 41, 661-664 
9. Wahr, J. A., Yun, J. H., Yang, V. C., Lee, L. M., Fu, B., Meyerhoff, M. E. (1996) A new method of measuring heparin levels in whole blood by protamine titration utilizing a heparin-responsive electrochemical sensor. $J$. Cardiothor. Vasc. Anesth. 10, 447-450

10. Fu, B., Bakker, E., Yun, J. H., Yang, V. C., and Meyerhoff, M. E. (1994) Response mechanism of polymer membrane-based potentiometric polyion sensors. Anal. Chem. 66, 2250-2259

11. Fu, B., Bakker, E., Yang, V. C., and Meyerhoff, M. E. (1995) Extraction thermodynamics of polyanions into plasticized polymer membranes doped with lipophilic ion exchangers: A potentiometric study. Macromolecules 28, 5834-5840
12. Harrell, J. B., Jones, A. D., and Choppin, G. R. (1969) A liquid ion-exchange membrane electrode for polyvalent cations. Anal Chem. 41, 1459-1462

13. Schaller, U., Bakker, E., Spichiger, U. E., and Pretsch, E. (1994) Ionic additives for ion-selective electrodes based on electrically charged carriers. Anal. Chem. 66, 391-398

14. Telting, M., Collison, M. E., and Meyerhoff, M. E. (1994) Simplified duallumen catheter design for simultaneous potentiometric monitoring of carbon dioxide and $\mathrm{pH}$. Anal. Chem. 66, 576-583

Received for publication April 7, 1996. Accepted for publication August 16, 1996. 